\title{
A EFETIVAÇÃO DOS DIREITOS ECONÔMICOS, SOCIAIS E CULTURAIS PELO PODER JUDICIÁRIO: O PROJETO DE LEI N. 8.058/2014 E OS DESAFIOS EM SEDE DE CONTROLE JURISDICIONAL DE POLÍTICAS PÚBLICAS
}

\author{
THE ENFORCEMENT OF ECONOMIC, SOCIAL AND CULTURAL RIGHTS BY THE JUDICIARY: THE \\ BILL N. 8.058/2014 AND THE CHALLENGES TO JUDICIAL REVIEW OF PUBLIC POLICIES
}

Mônia Clarissa Hennig Leal* Felipe Dalenogare Alves**

Resumo: Neste trabalho expõe-se o resultado de uma pesquisa bibliográfica, utilizando-se os métodos dedutivo, para fins de abordagem, e monográfico, a título procedimental, sobre a temática da efetivação dos direitos econômicos, sociais e culturais (DESCs) pelo Judiciário. O objetivo principal foi analisar as peculiaridades que envolvem esses direitos e a sua concretização judicial pelo controle das políticas públicas. Para tanto, realizou-se um estudo dos principais aspectos referentes ao tema, com a construção teórica acerca dos DESCs e sua difícil efetivação pelas políticas públicas, além do seu controle jurisdicional, para, posteriormente, realizar uma análise sistemática do Projeto de Lei n. 8.058/2014, que visa estabelecer um processo especial para o controle jurisdicional de políticas públicas, levantando seus principais avanços no sentido de contribuir para a modernização processual, especialmente quando se trata da tutela dos DESCs, diante das principais dificuldades arguidas como fundamentos na exposição de motivos. No decorrer do trabalho, buscou-se o esclarecimento de questões importantes à temática, como o seguinte problema: quais as peculiaridades próprias aos direitos econômicos, sociais e culturais que dificultam sua concretização e qual a necessidade e as vantagens de um Processo especial para o controle jurisdicional de políticas públicas? Por fim, concluiu-se que o Projeto apresenta importantes instrumentos no sentido de modernizar o processo judicial, principalmente no sentido de oportunizar uma tutela coletiva dos DESCs, possuindo, também, dispositivos que devem ser objeto de aperfeiçoamento no decorrer do processo legislativo.

Palavras-chave: Controle jurisdicional de políticas públicas. Direitos econômicos, sociais e culturais. DESCs. Judicialização. Projeto de Lei n. 8.058/2014.

\footnotetext{
Pós-doutora em Direito pela Ruprecht-Karls Universität Heidelberg, Alemanha; Doutora em Direito pela Universidade do Vale do Rio dos Sinos; Professora e Coordenadora Adjunta do Programa de Pós-Graduação em Direito (Mestrado e Doutorado) na Universidade de Santa Cruz do Sul; Avenida Independência, 2293, Universitário, 96800-000, Santa Cruz do Sul, Rio Grande do Sul, Brasil; moniah@unisc.br

"Mestre e doutorando pelo Programa de Pós-Graduação Stricto Sensu em Direito da Universidade de Santa Cruz do Sul; Professor do Curso de Direito na Faculdade Antonio Meneghetti; Estrada Recanto Maestro, 338, 97200-000, Restinga Sêca, Rio Grande do Sul, Brasil; felipe@estudosdedireito.com.br
} 


\begin{abstract}
In this paper it was presented the results of a bibliographical research, developed using the phenomenological-hermeneutical method, about the enforcement of economic, social and cultural rights (ESCR) by the Judiciary, aiming to analyze the peculiarities involving these rights and its implementation by the judicial review of public policies. Therefore was performed a study of the main aspects related to the theme, with special accent on the theoretical aspects of ESCR and the difficulty related to their concretization through public policies, beyond its jurisdictional control, to proceed subsequently to a systematic analysis of the Bill n. 8.058/2014, which aims to establish a special procedure for judicial review of public policy, pointing out its key advances in order to contribute to the procedural modernization of ESCR rights protection, especially in what concerns to the difficulties exposed in its Explanatory Memorandum. The work tries to clarify important issues to the theme, considering the following problem: what are the peculiarities to economic, social and cultural rights that hinder its implementation and what are the advantages of a special process for judicial review of public policies? Finally, it is concluded that the project has important instruments to modernize the judicial process, especially in order to create opportunities to the collective protection of ESCR, presenting, however, also some devices that still need to be improved during the legislative process.
\end{abstract}

Keywords: Judicial review of public policies. Economic, social and cultural rights. ESCR. Judicialization. Bill n. 8.058/2014.

\title{
Introdução
}

O presente trabalho é resultado de uma pesquisa que teve por objetivo principal a investigação acerca das peculiaridades que envolvem os direitos econômicos, sociais e culturais (DESCs), bem como sua concretização pelo Poder Judiciário, por intermédio do controle das políticas públicas. A busca da tutela jurisdicional dos direitos fundamentais, especialmente no que se refere aos DESCs, diante da ordem constitucional contemporânea, tornou-se cada vez mais frequente, o que, como se constata no decorrer do artigo, compreende-se como fenômeno comum, principalmente em países da América Latina, África e Leste Europeu.

No Brasil, considerando a existência de uma "Constituição Cidadã", dotada de direitos fundamentais, particularmente os sociais, o indivíduo não apenas dispõe de seus direitos, como também de ferramentas processuais (em sua maioria pensadas por um prisma individual), para procurar o Judiciário na busca por satisfação do seu complexo direito (diante da dimensão coletiva e ao mesmo tempo individual que possui).

Esses direitos (que, em regra geral, contemplam uma dimensão concomitantemente positiva e negativa) são efetivados, em grande medida, por políticas públicas, pensadas, deliberadas e implementadas pelos poderes políticos, dentro de um processo complexo, contínuo e dinâmico.

Ocorre que, ao se buscar no Poder Judiciário a tutela dos DESCs, inevitavelmente, aquele acaba exercendo o controle jurisdicional das políticas públicas, que, por vezes, recebe críticas em relação à falta de parâmetros e critérios, demonstrando, assim, a necessidade de desenvolvimento e aprimoramento dos instrumentos processuais, tradicionalmente pensados pela perspectiva dos direitos civis e políticos (espectro individual).

Com isso, somado a dificuldades como falta de informações, ausência ou inexatidão de dados, inexistência ou ineficácia de assessoria técnica, de contatos da própria Administração encarregada da implementação dessas políticas públicas, bem como de contatos com os demais juízes e 
tribunais, ainda e não obstante dificuldades de ordem orçamentária e as oriundas da multiplicidade de ações individuais que inevitavelmente incidem sobre essas políticas, apresentou-se, no dia 04 de novembro de 2014, à Câmara dos Deputados, o Projeto de Lei n. 8.058/2014, de autoria do Deputado Paulo Teixeira (PT-SP), que objetiva instituir processo especial ao controle e à intervenção em políticas públicas pelo Poder Judiciário.

O projeto contempla instrumentos, atualmente já empregados parcialmente com maior ou menor intensidade, objetivando proporcionar maior segurança e critérios à tomada de decisão judicial, por meio de inovações consideráveis, como a possibilidade de conversão da ação individual em coletiva e a realização de audiências públicas, além da intervenção de amicus curiae.

Nesse contexto, o problema apresentado à pesquisa foi: quais as peculiaridades próprias aos direitos econômicos, sociais e culturais que dificultam sua concretização? Ainda, qual a necessidade e as vantagens de um processo especial para o controle jurisdicional de políticas públicas?

A fim de contemplar a consecução dos objetivos propostos, a pesquisa bibliográfica desenvolveu-se por meio do emprego do método fenomenológico-hermenêutico, para fins de abordagem, eis que o fenômeno é essencial para o desvelamento da realidade, e, ainda, do método monográfico, a título procedimental, analisando-se, assim, os elementos essenciais ao tema, bem como a doutrina nacional e estrangeira, a legislação pertinente e a jurisprudência relativa.

Dessa forma, buscou-se, na primeira seção do trabalho, uma construção teórica acerca dos DESCs e da sua complexa efetivação em face às políticas públicas, além do referente controle jurisdicional destas, para, em uma segunda seção, desenvolver a análise sistemática do Projeto de Lei n. 8.058/2014, pontuando-se os principais avanços, no sentido de contribuir à modernização do processo judicial, especialmente no que se refere à tutela dos DESCs, diante das principais dificuldades arguidas como fundamentos na exposição de motivos.

\section{Direitos econômicos, sociais e culturais: sua estrutura, justiciabilidade e efetivação pelas políticas públicas}

Os direitos econômicos, sociais e culturais (DESCs), tidos como direitos fundamentais de segunda geração (ou dimensão), relativos à igualdade em um sentido material, são, em grande parte, denominados direitos prestacionais ou direitos positivos, visto que exigem prestação positiva por parte do Estado para que se atinja sua consecução, ${ }^{1}$ sem deixar de considerar, todavia, que estes se encontram correlacionados aos direitos civis e políticos (DCPs), pois, ao fim, mesmo que indiretamente, servem à sua concretização.

Muito embora os direitos sociais tenham sido contemplados nas primeiras décadas do século XX (eclodindo à Constituição mexicana de 1917 e à Constituição de Weimar de 1919), no Brasil

\footnotetext{
1 Não se desconsidera, aqui, que os direitos civis e políticos também se caracterizam por um conjunto de obrigações negativas e positivas por parte do Estado - obrigação de abster-se de violá-los e, ao mesmo tempo, de realizá-los, garantindo a autonomia individual e impedindo sua violação entre os pares (ABRAMOVICH; COURTIS, 2002, p. 24). A respeito, ver a crítica traçada por Holmes e Sunstein (2012, p. 55 e ss.) quanto à dicotomia (direitos negativos e positivos). Para os autores, todos os direitos são positivos.
} 
(ainda que a primeira Constituição a contemplá-los tenha sido a de 1934), ${ }^{2}$ ainda representam um paradigma a ser constantemente transposto, particularmente por demandar um Estado prestacional, compatível com o Estado Social.

Nesse sentido, há de se compreender que os direitos econômicos, sociais e culturais não se constituem como mera forma de reparar injustiças, tampouco como subsidiários aos direitos civis e políticos, mas incorporam a estes uma dimensão social, na busca de igualdade material e de liberdade real $^{3}$ (BARRETTO, 2012, p. 3). É essa encampação da dimensão social que leva Bucci (2006, p. 3) a se referir aos primeiros, como "direitos-meio", eis que visam garantir o exercício pleno dos últimos.

De fato, pode-se dizer que os direitos de segunda dimensão foram pensados a partir dos direitos individuais. Essa é, inclusive, uma das dificuldades enfrentadas para o estabelecimento de um entendimento das peculiaridades próprias dos direitos sociais, principalmente no que se refere ao seu conteúdo, às suas características e seus titulares, construídos e concretizados por uma perspectiva social, mesmo que, ao fim, acabem concretizando um direito individual. Como exemplo, tem-se que, sem a efetividade do direito à saúde (social), não há a manutenção do direito à vida (individual).

Canotilho (2004, p. 100) afirma, nesse contexto, que “[...] paira sobre a dogmática e teoria jurídica dos direitos econômicos, sociais e culturais a carga metodológica da 'vaguidez', 'indeterminação' e 'impressionismo'", que o autor denomina de "fuzzysmo" ou "metodologia fuzzy", para se referir à vagueza e imprecisão com que esses direitos são tratados. Isso decorre, em certa medida, do conteúdo híbrido desses direitos, eis que, ao mesmo tempo, constituem-se direitos de defesa ${ }^{4}$ e prestacionais, o que dificulta o estabelecimento de uma categoria jurídica autônoma (GAVARA DE CARA, 2010, p. 38).

A necessidade de superação dessa dificuldade é apontada por Sarlet (2009, p. 483), ao afirmar que, no estudo dos direitos sociais, não há como prescindir de uma abordagem por uma perspectiva "dogmático-jurídica", ou seja, a partir de uma "[...] leitura constitucionalmente adequada da própria fundamentação (inclusive filosófica) tanto da assim designada fundamentalidade quanto do próprio conteúdo dos direitos sociais."

Reconhece-se, assim, a dificuldade da tarefa. Abramovich e Courtis (2002, p. 24-26) elaboram entendimento ao pontuar que a diferença entre esses direitos e os direitos civis e políticos contempla, sobretudo, grau, mais que substância. Isso em razão de os DESCs compreenderem também uma face negativa, significando dizer que a cada direito positivo se tem sua correspondência negativa (a cada obrigação de fazer, há uma obrigação de não fazer). Isso se torna visível (destacando-se um exemplo) no direito à saúde (há o dever estatal de proporcionar os meios de prevenção e promoção

\footnotetext{
2 É oportuno ressaltar que a Constituição imperial outorgada em 1824, a qual vigorou por 65 anos, sendo emendada uma única vez, assegurou a previsão tímida, no mesmo rol dos direitos individuais, de direitos como a educação e os socorros públicos, de caráter social (BRASIL, 1824).

3 Torna-se pertinente a observação de Böckenförde (1993, p. 64) no sentido de que a teoria dos direitos fundamentais do Estado Social pretende superar o desdobramento entre a "liberdade jurídica" e a "liberdade real", isso porque, por essa perspectiva, os direitos fundamentais (em sentido lato) já não podem ser vistos unicamente por um caráter limitador-negativo, mas, ao mesmo tempo, impõem prestações sociais diante do Estado.

4 A exemplo do direito de greve, da liberdade de associação sindical, das proibições de discriminação entre os trabalhadores (direitos especiais de igualdade).
} 
da saúde e a obrigação de não causar dano à saúde dos particulares). Os mesmos autores assinalam, ainda, outro problema conceitual que torna difícil a distinção radical entre os DCPs e os DESCs, qual seja o tratamento substancial comum a ambos os direitos.

Assim, diz-se que não ocorre apenas o que se pode cunhar "individualização dos direitos sociais", mas também "socialização dos direitos individuais", ou seja, não são apenas os direitos sociais que passam a ser vistos por um viés individual, mas os direitos individuais passam a contemplar uma perspectiva social.

Nessa tangente, basta analisar-se o trato social dado ao direito de propriedade, antes tido como direito individual absoluto. Além disso, percebe-se a "socialização" que dá novos contornos ao direito à liberdade de expressão e de imprensa, que, em nome de um direito à informação, transcende o indivíduo e passa a pertencer à sociedade (ABRAMOVICH; COURTIS, 2002, p. 26).

A crise de identidade dos direitos sociais reflete diretamente na dúvida que paira sobre os atores sociais detentores da titularidade ${ }^{5}$ desses direitos. ${ }^{6}$ São direitos voltados ao indivíduo ou à coletividade? São efetivados individualmente? Essas questões são fundamentais à análise pretendida na última seção do presente artigo.

Arango (2005, p. 59-60) defende enfaticamente que se tratam de direitos cuja titularidade pertence ao indivíduo, isto é, à pessoa natural. Para o autor, não são metas políticas, tampouco direitos coletivos, eis que os grupos de indivíduos não são considerados titulares de direitos sociais, pois os DESCs são direitos destinados, individualmente, às pessoas naturais.

Há de se dizer que a diferenciação historicamente conhecida entre direitos individuais e sociais não ocorreu em razão da titularidade (individual ou social), mas em virtude de que direitos como saúde, educação, moradia, jornada de trabalho, etc., foram conquistas advindas das reivindicações dos movimentos sociais, considerando-se cada pessoa individualmente (SARLET, 2010, p. 215).

A tese do autor brasileiro vai ao encontro do entendimento do Supremo Tribunal Federal, de que os DESCs (ao menos o direito à saúde, que foi objeto dos julgados) são direitos públicos subjetivos, ${ }^{7}$ coabitando uma titularidade simultaneamente individual e coletiva. Em outras palavras, significa dizer que o indivíduo (dentro da sociedade) não pode deixar de ser titular de um direito concreto (educação, saúde, alimentação, trabalho, moradia, lazer, segurança, previdência social, pro-

\footnotetext{
5 Neste trabalho, é adotada a distinção semântica estabelecida por Sarlet (2010, p. 208), no sentido de que a expressão "[...] titular de direito fundamental" não é sinônimo de "[...] destinatário de direito fundamental", isso porque "[...] titular do direito, notadamente na perspectiva da dimensão subjetiva dos direitos e garantias fundamentais, é quem figura como sujeito ativo da relação jurídico-subjetiva, de tal sorte que destinatário é a pessoa (física, jurídica ou mesmo ente despersonalizado) em face da qual o titular pode exigir o respeito, proteção ou promoção do seu direito."

6 Fala-se em crise de identidade, não no sentido de que, necessariamente, devesse haver uma identidade única que caracterizasse os direitos sociais. Isso fica claro no decorrer do trabalho, principalmente com a construção de que os direitos fundamentais são indivisíveis e interdependentes. Nesse sentido, "[...] se apresentam como direitos complexos, em parte positivos, em parte negativos; em parte custosos, em parte não custosos; em parte individuais, em parte coletivos; em parte universais e em parte específicos." (PISARELLO, 2007, p. 75).

7 Essa dimensão individual dos DESCs, em especial a saúde, foi inicialmente traçada pelo Ministro Celso de Mello, no AgR-RE 271.286-8/RS, ao reconhecer o direito à saúde como um direito público subjetivo, o qual estabelece uma relação jurídica entre indivíduo e Estado. Esse entendimento foi consolidado posteriormente pelo Ministro Gilmar Mendes, por ocasião do julgamento conjunto das STA 175, 211 e 278, SS 3724, 2944, 2361, 3345 e 3355 e SL 47.
} 
teção à maternidade e à infância e assistência aos desamparados, por exemplo), eis que, dentro da coletividade, ele é o titular do bem jurídico tutelado.

A propósito do que questionam Abramovich e Courtis (2002, p. 47-48), há algum sentido em manter a distinção entre direitos individuais e direitos sociais? Para os autores, a distinção somente é útil para refletir as diferentes matrizes político-ideológicas de sua regulamentação jurídica e para, historicamente, demonstrar a forma pela qual foram idealizados e positivados.

Pisarello (2007, p. 59) tece crítica a três teses que tentam estabelecer uma diferença estrutural entre os DESCs e os DCPs, as quais, embora e, na maioria das vezes, pautem-se em argumentos históricos, axiológicos e dogmáticos, derivados dos distintos ordenamentos jurídicos, constituem, conforme o autor, "prejuízos ideológicos suscetíveis de refutação" ou objeções que poderiam se destinar a todos os direitos fundamentais e não apenas aos DESCs.

A primeira tese pontua que os DESCs são direitos exclusivamente prestacionais e possuem elevado custo. A crítica do autor corrobora a concepção já traçada anteriormente, de que "[...] nem os direitos civis e políticos podem caracterizar-se só como direitos negativos, de abstenção, nem os direitos sociais atuam sempre como direitos positivos, de prestação." (PISARELLO, 2007, p. 60). Como exemplo, destaca-se o direito à propriedade (questionando o custo ao Estado à segurança pública) e o direito ao sufrágio universal (inquirindo o custo de um processo eleitoral ao Estado).

A segunda tese aloca-se na ideia de que os DESCs constituem direitos vagos e indeterminados. Para aqueles que fazem disso um óbice, conceitos como "moradia" representam a vagueza do conteúdo concreto do direito, diferentemente dos DCPs, que possuem enunciado mais completo, não apenas prevendo um objetivo, mas, também, os meios que provocam sua vulneração. Ao criticar a concepção, o autor destaca que a indeterminação não apenas é comum na linguagem jurídica, mas, também, natural, além de não estar presente apenas nos DESCs. Dessa forma, questiona-se: qual a maior precisão encontrada em direitos como "honra" e "liberdade de expressão"? (PISARELLO, 2007, p. 67).

A terceira tese se refere à visão de que os DESCs são direitos específicos de dimensão coletiva. A crítica traçada pelo autor vai ao encontro da concepção supraexposta, construída por meio da ideia de Sarlet (2010) e do próprio STF, no sentido de que esses direitos (híbridos) também contemplam uma dimensão individual. Assim, a dimensão individual ou coletiva de um direito fundamental relaciona-se a diferentes fatores, entre os quais os valores que o direito persegue, os bens jurídicos tutelados, seus titulares e seus legitimados (PISARELLO, 2007, p. 72).

De toda sorte, o que não se pode desconsiderar é que os DESCs, em sua grande maioria, são realizáveis por (e dependentes) de políticas públicas, as quais se destinam à coletividade, objetivando a concretização de um direito cujo titular é um sujeito que, em um primeiro momento é indeterminado, mas que, ao exercê-lo, torna-se determinado. ${ }^{9}$

\footnotetext{
8 Para aprofundamento da crítica do autor, indispensável a leitura complementar de Holmes e Sunstein (2012) já citada em nota anterior.

9 Em termos práticos, pode-se dizer: O Estado não realizará uma política pública de saúde específica para o cidadão João (sujeito determinado), mas para toda a coletividade (sujeito indeterminado), característica da política pública. Porém, no momento em que João necessitar de um atendimento médico (elemento dessa política pública voltada a sujeitos indeterminados), tem-se a personificação do sujeito e o exercício individual do direito à saúde.
} 
Nesse prisma, conjectura-se que cada direito (subjetivo) corresponde a uma meta política (objetiva), e nesse ponto reside a relação sujeito-Estado. Por exemplo, ao direito (do indivíduo) ao trabalho corresponde a obrigação (do Estado) em elaborar e implementar uma política pública que proporcione ao indivíduo a possibilidade laboral (ARANGO, 2005, p. 64).

Admitindo-se que os direitos econômicos, sociais e culturais guardam uma dimensão subjetiva, busca-se a possibilidade de tutela destes no Poder Judiciário, fenômeno que, especialmente nas últimas duas décadas, é crescente não apenas no Brasil, mas, também, no direito comparado, o que se demonstra a seguir.

Ínfimas são as decisões judiciais envolvendo DESCs no século XX, embora sua presença e possibilidade de exigibilidade já estivessem alocadas e contempladas por grande parte das Constituições, além do próprio direito administrativo. Nesse sentido, eclodiram algumas decisões isoladas, como o caso Numerus Clausus na Alemanha (LANGFORD, 2009, p. 99).

O mesmo não se pode dizer das últimas duas décadas. Langford (2009, p. 99) estima que, até o ano 2009, somavam-se entre 100 e 200 mil decisões judiciais envolvendo os DESCs, visto que mais de 10 mil casos contemplavam o contexto brasileiro (número ínfimo comparado aos dados de 2015, expostos em sequência), mesmo quantitativo aproximado de países como Colômbia e Costa Rica.

A jurisdição indiana tem sido reconhecida como pioneira no desenvolvimento de uma jurisprudência relativamente avançada acerca dos DESCs, especialmente a partir da década de $1980 .{ }^{10}$ Posteriormente, a Corte Constitucional da África do Sul destacou-se no cenário internacional, particularmente pela racionalidade de suas decisões envolvendo os DESCs. ${ }^{11} \mathrm{O}$ pioneirismo não impede algo que é comum a ambas as jurisdições: a crítica ${ }^{12}$ (LANGFORD, 2009, p. 99-101).

No Brasil, a judicialização dos DESCs, em especial o direito à saúde, atingiu números que, até os dias de hoje, em nível nacional, continuam imensuráveis. O Conselho Nacional de Justiça (CNJ), no ano 2015, divulgou pesquisa que objetivou, por amostragem, levantar dados (ainda iniciais) a respeito do número de processos judiciais envolvendo o direito à saúde.

Diante disso, constatou-se, apenas considerando os julgados dos Tribunais de Justiça dos Estados de São Paulo, Paraná, Rio Grande do Norte, Minas Gerais, Mato Grosso do Sul e Acre, que os números

\footnotetext{
10 Isso ocorreu principalmente a partir do caso Municipal Council Ratlam vs. Vardhichand and others (em 1980), no qual a Suprema Corte determinou à municipalidade que cumprisse a obrigação estatal de fornecimento de água e prestação de serviços de esgoto e saneamento e, posteriormente, no caso Bandhua Mukti Morcha vs. Union of India (em 1984), no qual se interpretou o direito à vida de forma que abarcasse uma gama de direitos econômicos sociais e culturais (LANGFORD, 2009, p. 100).

11 O caso pioneiro é Government of the Republic of South Africa and Others vs. Grootboom and Others (em 2000), no qual a Corte determinou que as autoridades do governo deveriam tomar medidas legislativas e outras que fossem razoáveis, dentro dos recursos disponíveis, para implementar progressivamente o direito à moradia, uma vez que os programas do governo não ofereciam auxílio emergencial algum àqueles que não possuíam acesso a um abrigo básico. Posteriormente, apenas para destacar alguns, surgiram os casos Minister of Health and Others vs. Treatment Action Campaign and Others (em 2002) envolvendo a implementação de políticas preventivas à transmissão do vírus HIV de mãe para filho e os casos Mahlaule vs. Minister of Social Development e Khosa vs. Minister of Social Development (em 2004), nos quais se estendeu aos emigrantes o direito à seguridade social, além de decisões envolvendo o reassentamento de famílias, a partir do caso Port Elizabeth vs. Various Occupiers (também em 2004) (LANGFORD, 2009, p. 100-101).

12 A jurisdição indiana pelo conservadorismo de suas decisões, principalmente nas que envolvem os direitos dos trabalhadores, o direito à moradia e à terra. A sul-africana pela fragilidade de suas decisões baseadas em critérios de razoabilidade, pouco eficazes diante das obrigações estatais, a exemplo do caso City of Johannesburg and Others vs. Lindiwe Mazibuko and Others (em 2009), envolvendo o direito à água.
} 
envolvendo a saúde pública e suplementar, entre os anos 2011 e 2012, ascendem a 33.615 decisões. Os números referem-se exclusivamente a acórdãos e decisões monocráticas proferidas em segunda instância, desconsiderando-se os números da Justiça Federal (ASENSI; PINHEIRO, 2015, p. 19-26).

O volume de processos judiciais envolvendo os DESCs provém, em grande parte, da estrutura jurídica que se proporcionou a esses direitos. Significa dizer que essa "explosão" de casos judiciais envolvendo esses direitos está diretamente relacionada à sua "constitucionalização", mormente em países da América Latina, África e Leste Europeu. Por outro lado, no que se refere à jurisprudência intercorrente aos DESCs, tem-se que não se desenvolve de forma uniforme nos mesmos países (LANGFORD, 2009, p. 102-103).

Diante disso, observa-se a evolução da jurisprudência sul-africana, por exemplo, em relação à brasileira, posto a primazia daquela pela efetivação coletiva do direito, atuando como indutora de políticas públicas, enquanto no Brasil há predominância de uma atuação voltada à efetivação individual do direito, colocando em conflito, de um lado, a efetivação individual do direito por meio das decisões judiciais e, de outro, a efetivação coletiva do direito por meio das políticas públicas.

As políticas públicas representam “[...] 'o Estado em ação', o resultado da política institucional e processual. As políticas se materializam em diretrizes, programas, projetos e atividades que visam resolver problemas e demandas da sociedade" (SCHMIDT, 2008, p. 2311), consubstanciando-se nas "[...] providências para que os direitos se realizem, [...] as satisfações sejam atendidas, [...] as determinações constitucionais e legais saiam do papel e se transformem em utilidade aos governados." (OLIVEIRA, 2006, p. 251).

Destarte, são oriundas de um complexo processo de elaboração e execução, em que os problemas sociais são percebidos, definidos e inseridos à agenda política, a fim de elencarem objeto de formulação da política, a qual, posteriormente ao debate e à deliberação em arena política, será implementada e, por fim, avaliada (SCHMIDT, 2008, p. 2315).

É essa complexidade que leva Bucci (2006, p. 39) a destacar que:

Política pública é o programa de ação governamental que resulta de um processo ou conjunto de processos juridicamente regulados - processo eleitoral, processo de planejamento, processo de governo, processo orçamentário, processo legislativo, processo administrativo, processo judicial — visando coordenar os meios à disposição do Estado e as atividades privadas, para a realização de objetivos socialmente relevantes e politicamente determinados.

Não obstante, reconhece-se que a apreciação jurisdicional envolvendo os direitos sociais interfere diretamente nas políticas públicas, como conclui o próprio Conselho Nacional de Justiça ao estabelecer que "[...] qualquer intervenção judicial que seja mais contínua e perene pode influenciar decisivamente o rumo das políticas públicas do ponto de vista do orçamento, planejamento, gestão, riscos, etc." (ASENSI; PINHEIRO, 2015, p. 131).

O processo de judicialização dos DESCs acaba ilustrando a "processualidade das políticas públicas", submetendo-as, cada vez mais, à apreciação do Poder Judiciário, desencadeando-se, assim, uma necessidade de modernização do processo judicial (BUCCI, 2013, p. 192). Essa necessidade de adequação processual também é apontada por Abramovich e Courtis (2003, p. 73), na medida em 
que "[...] as ações judiciais tradicionais tipificadas pelo ordenamento jurídico foram pensadas para a proteção dos direitos civis clássicos."

Nesse caminho de aprimoramento processual, apresentou-se à Câmara dos Deputados, no dia 04 de novembro de 2014, o Projeto de Lei n. 8.058/2014, de autoria do Deputado Paulo Teixeira (PT-SP), que objetiva, entre outras providências, instituir um processo especial para o controle e a intervenção em políticas públicas pelo Poder Judiciário, o qual será o objeto de análise da seção a seguir.

\section{0 projeto de Lei n. 8.058/2014: uma análise das (des)vantagens de um procedimento especial para o Controle Jurisdicional de Políticas Públicas}

O Projeto de Lei n. 8.058/2014, de autoria do Deputado Paulo Teixeira (PT-SP), apresentado em 04 de novembro de 2014, objetiva, entre outras providências, instituir processo especial para o controle e a intervenção em políticas públicas pelo Poder Judiciário. Analiticamente, sistematizaram-se os principais fundamentos utilizados na exposição de motivos, categorizando-se os dispositivos legais que viriam a sanar essas dificuldades.

Na exposição de motivos, admite-se que "[...] o controle jurisdicional de políticas públicas é uma realidade presente no dia a dia dos tribunais brasileiros." Entre os argumentos julgados importantes, encontra-se o que relaciona algumas dificuldades enfrentadas pelo juiz, como:

1) a falta de informaçôes e de dados; 2) a falta de assessoria técnica; 3) a falta de contatos com a própria Administração encarregada da implementação da política pública; 4) a falta de contatos com os demais juizes e tribunais; 5) as dificuldades de ordem orçamentária; e 6) as dificuldades oriundas da multiplicidade de ações individuais que vão inevitavelmente incidir sobre as políticas públicas. (CÂMARA DOS DEPUTADOS, 2014, grifo nosso).

Objetivando-se superar essas dificuldades, o projeto contempla dispositivos e ferramentas processuais, alguns já empregados, outros inexistentes, que serão analisados e confrontados, apontando-se, com base na doutrina e na legislação, suas vantagens e oportunidades de aprimoramento.

\subsection{Da falta de informações e dados}

O Art. 26 do projeto prevê que o CNJ “[...] organizará e manterá o Cadastro Nacional de Processos sobre Políticas Públicas, com a finalidade de permitir que os órgãos do Poder Judiciário e os interessados tenham amplo acesso às informações relevantes relacionadas com sua existência e estado." (CÂMARA DOS DEPUTADOS, 2014).

Em pesquisa, anteriormente referida, publicada em 2015, sobre a judicialização da saúde, o CNJ apontou que um de seus maiores desafios era (e continua sendo) justamente a "quantificação das demandas", naquele caso, envolvendo apenas o direito à saúde. Em sede de conclusão, os pesquisadores encarregados afirmam que há "[...] uma relativa indisponibilidade de dados a respeito do Judiciário brasileiro, especialmente da $1^{a}$ instância." (ASENSI; PINHEIRO, 2015, p. 136). 
A situação não se conjectura como isolada, pairando sobre o Poder Judiciário como um todo, pois "[...] em praticamente todos os tribunais, observa-se uma dificuldade de acesso aos dados processuais, tipos de ação, tempo de conclusão etc." Embora haja determinado avanço na segunda instância e nos tribunais superiores, "[...] é preciso também apresentar os dados da $1^{\text {a }}$ instância aberta e diretamente." (ASENSI; PINHEIRO, 2015, p. 136).

Assim, anuncia-se que "[...] não há dúvidas de que é preciso ampliar a disponibilidade dos dados para que se possa conhecer melhor, e com rigor científico, o Judiciário." (ASENSI; PINHEIRO, 2015, p. 136). Nesse sentido, o cadastro mantido pelo CNJ viria a somar e, por fim, proporcionar informações que contribuíssem para a mensuração e a detecção dos principais problemas, de forma a atuar preventivamente na implementação das políticas ou na correção das deficientes, diminuindo, assim, a judicialização.

Ainda em relação ao cadastro nacional, o projeto estabelece, no Art. $26, \mathbb{\$} 1^{\circ}$, que "Os órgãos judiciários aos quais forem distribuídos processos envolvendo controle de políticas públicas remeterão cópia da petição inicial, preferencialmente por meio eletrônico, ao Cadastro Nacional do Conselho Nacional de Justiça, no prazo de 10 (dez) dias." (CÂMARA DOS DEPUTADOS, 2014).

Coloca-se, assim, a necessidade de aprimoramento do texto original, em face à indubitável inviabilidade fática dessa exigência. Nesse aspecto, deverá haver um aprimoramento, com a sistematização das informações, em cadastro eletrônico próprio, de forma a conter apenas dados essenciais, sob pena de transformar o CNJ em depósito de petições.

Objetivando-se munir o magistrado de informações detalhadas, o Art. $6^{\circ}$ prevê o prazo de 60 dias (com possibilidade de prorrogação por igual período) para que a autoridade responsável pela efetivação da política preste pessoalmente, no mínimo, as seguintes informações sobre a política que será objeto de controle:
a) o planejamento e a execução existentes;
b) os recursos financeiros previstos no orçamento para a sua implementação;
c) a previsão de recursos necessários à sua implementação ou correção;
d) em caso de insuficiência de recursos, a possibilidade de transposição de verbas;
e) o cronograma necessário ao eventual atendimento do pedido.

O questionamento que surge a partir da obrigatoriedade das informações é: comprovados os requisitos constantes nas informações anteriores, como agirá o juiz? Abster-se-á de controlar a política pública? Do contrário, em que auxiliará a comprovação de todos os requisitos por parte da autoridade pública? O projeto prevê que "[...] se não prestadas as informações indicadas no caput, o juiz aplicará à autoridade responsável as sanções previstas no Código de Processo Civil, podendo convocá-la pessoalmente para comparecer a juízo." (CÂMARA DOS DEPUTADOS, 2014).

Conceitua-se que as informações servirão (e somente!) para a formação do juízo de convicção do magistrado, embora sirvam à condução de dados fundamentais ao conhecimento judicial, 
visto que, provável se faz, que as informações pouco influenciem a decisão que concretizará o direito econômico, social ou cultural em jogo.

\subsection{Da falta de assessoria técnica}

No Art. $8^{\circ}, \mathbb{\$} 2^{\circ}$, o projeto prevê a possibilidade do julgador em empregar " [...] técnicos especializados para assessorá-lo na análise das informações, sem prejuízo de consulta a órgãos e instituições do ramo." Processualmente, não apresenta nada diverso da realidade fática atual. Também estipula que "[...] na prestação de informações, a autoridade responsável pela execução da política pública poderá servir-se de assessores técnicos especializados." (CÂMARA DOS DEPUTADOS, 2014).

Descortina-se, assim, que essa previsão reproduz o que, na prática, já ocorre na atualidade. Diz-se isso porque a desqualificação técnica, que, em muitos casos, já ocorre no âmbito dos Poderes, permanecerá. A administração dispõe de todos os meios para se servir de serviços técnico-especializados, seja por intermédio de seus quadros (servidores), seja por meio de contrato administrativo (terceiros). Atualmente, não há nenhum impedimento ao desígnio, por parte do juiz, de peritos e das partes, de assistentes técnicos.

Por certo, o julgador deve se utilizar de assessoria e esse dever já existe. O que falta é sua aplicação prática. Ao dispensar assessoria técnica e "[...] formular políticas públicas que atendam às suas prioridades pessoais", os juízes "[...] se lançam em verdadeira aventura política." (APPIO, 2006, p. 71).

O projeto contempla, em seu Art. 10, a possibilidade de realização de audiências públicas, convocando representantes da sociedade civil, de instituições e órgãos especializados, admitindo-se, também, na fase preliminar e no processo judicial, a intervenção de amicus curiae, pessoa física ou jurídica, que poderá se manifestar oralmente ou por escrito.

Assim, mesmo na constituição de práticas já previstas, a exemplo do amicus curiae (contemplado no novo Código de Processo Civil), ao possibilitar a abertura da jurisdição, com a participação da sociedade e de especialistas, contribui positivamente o projeto, corroborando o que Langford (2009, p. 107) já pontuava, no sentido de que "[...] as instituições com funções judiciais têm respondido a este desafio de falta de informação fazendo uso de órgãos especializados, peritos e petições de amicus curiae, um fenômeno que tem sido adotado no âmbito de casos sobre DESC."

\subsection{Da falta de contatos com a própria Administração encarregada da implementação da política pública}

Essa dificuldade (e necessidade) foi apontada pelo próprio Conselho Nacional de Justiça, ao concluir que "no cotidiano de suas ações, as instituições jurídicas têm a atribuição de atuar na efetivação do direito à saúde, responsabilizando e dialogando com os diversos atores sociais envolvidos em sua concretização." (ASENSI; PINHEIRO, 2015, p. 133). 
O CNJ assinalou necessidade de se "[...] criar um espaço de diálogo, pois possibilita a comunicação entre os principais atores que compõem o processo de formulação, gestão e fiscalização das políticas públicas em saúde em um foro comum”. O diálogo que aponta o CNJ consiste no institucional preventivo, isto é, "[...] sem necessariamente ocorrer uma judicialização", baseado no recurso à oralidade (ASENSI; PINHEIRO, 2015, p. 134).

Essa concepção segue a linha traçada por Gargarella (2014), que denominou "Constitucionalismo Dialógico", ${ }^{13}$ o qual parte da premissa da construção de um diálogo institucional entre o Judiciário e os demais Poderes, com o objetivo da construção conjunta da decisão judicial e de terminar (ou minimizar) as tradicionais discussões acerca da legitimidade democrática da "última palavra". Assim, esta seria "construída" e não "imposta" (GARGARELLA, 2014).

Nesse sentido, mesmo que demande contribuição preventiva, o Projeto prevê espaços de diálogo, entretanto, mais direcionados ao exercício da ampla defesa e do contraditório (o que levaria à afirmação de que não se trata de diálogo), como a previsão contida no Art. $9^{\circ}$, de que o juiz poderá "[...] designar audiências, em contraditório pleno, inclusive com a presença dos técnicos envolvidos." (CÂMARA DOS DEPUTADOS, 2014).

Outra possibilidade é a previsão de "convocação" da autoridade pública, como exposto anteriormente, o que, ao menos prima facie, dificulta a horizontalidade do diálogo, perpassando uma visão de "vilão e mocinho" e não de diálogo interinstitucional, pois "[...] se não prestadas as informações indicadas no Art. $6^{\circ}$, o juiz aplicará à autoridade responsável as sanções previstas no Código de Processo Civil, podendo convocá-la pessoalmente para comparecer a juízo." (CÂMARA DOS DEPUTADOS, 2014).

Talvez a possibilidade de emprego de meios alternativos de solução de controvérsias, em qualquer tempo e em qualquer fase e grau do processo, prevista no Art. 11, viabilize uma resolução em que decorra preponderância de diálogo, por meio da mediação ou conciliação. $\bigcirc$ desafio que se propõe, entretanto, consiste na superação de uma cultura voltada ao litígio, seja por parte do titular do direto, seja de quem tem o dever de efetivá-lo (o Estado).

Em relação ao planejamento das políticas públicas, o projeto, no Art. $18, \mathbb{\$} 2^{\circ}$, de modo positivo, estabelece um compartilhamento de posições, fomentando o diálogo, eis que o planejamento necessário à implementação ou correção da política pública objeto da demanda “[...] será objeto

\footnotetext{
13 A noção de "Constitucionalismo Dialógico" é trabalhada na obra compilada por Roberto Gargarella, denominada Por una justicia dialógica: el Poder Judicial como promotor de la deliberación democrática, publicada em 2014. Alguns questionamentos realizados pelo compilador e por Paola Bergallo na apresentação da obra são capazes de fazer vir a luz muitas reflexões. Primeiro: "ípor qué es que los jueces, y no los legisladores, quedan a cargo de la tarea principal, em matéria de interpretación constitucional?" Segundo: "¿Por qué se da por sentado que los legisladores, en cuanto representantes del pueblo-de todos nosotros - van a conhecer menos, o van tratar peor que los jueces, los fundamentales valores constitucionales?" Terceiro: "i̇Es aceptable que, en el marco de una comunidad democrática, los jueces asuman el derecho a pronunciar la 'última palabra', respecto de cómo resolver los problemas constitucionales más básicos?" Quarto: "خ̇Por qué hemos adoptado un sistema institucional tan rígido, en que las relaciones entre los poderes aparecen marcadas por formas tan toscas como las hoy todavia dominantes (esto es, jueces que validan o invalidan una ley, como si los problemas constitucionales fueran del tipo 'todo o nada')"? Quinto: "íPor qué no es posible pensar en un diseño institucional diferente, en que los jueces - desde sus especiales conocimientos - ayuden a los legisladores em la creación de normas juridicamente más sólidas o menos cuestionables; o Poder Ejecutivo (em lugar de simplesmente 'vetar' o no una ley) comience a cooperar com los legisladores para que estos mejoren lo que han hecho?"
} 
de debate entre o juiz, o ente público, o autor, o Ministério Público e, quando possível e adequado, representantes da sociedade civil." (CÂMARA DOS DEPUTADOS, 2014).

Sequentemente, atribui ao Judiciário, no Art. 18, $\ 3^{\circ}$, após a homologação da proposta de planejamento, a incumbência periódica de avaliação da execução do projeto, com a participação das partes e do Ministério Público, e, caso este revele-se inadequado, deverá ser revisto, propiciando também o debate entre os atores sociais envolvidos.

Entre as conclusões do Conselho Nacional de Justiça (ASENSI; PINHEIRO, 2015, p. 134), tem-se que "O cenário da efetivação do direito à saúde, nos dias de hoje, passa não somente por uma relação estanque e episódica entre a sociedade, que figura como demandante, e o Estado, que é o responsável pela política (Executivo) ou por resolver conflitos (Judiciário)." Adentrando-se essa possibilidade, mesmo em espectro limitado, propiciaria-se maior horizontalidade não apenas na relação entre os Poderes, mas também na relação Estadosociedade.

Destarte, um acréscimo significativo à construção dialogada da decisão (embora venha a ocorrer somente na fase de execução) consiste na possibilidade de o juiz, de ofício ou a requerimento das partes, alterar a decisão, ajustando-a às peculiaridades do caso concreto. Dessa forma, deverá ocorrer também "Na hipótese de o ente público promover políticas públicas que se afigurem mais adequadas do que as determinadas na decisão, ou se esta se revelar inadequada ou ineficaz para o atendimento do direito que constitui o núcleo da política pública deficiente." (CÂMARA DOS DEPUTADOS, 2014). Esse dispositivo coloca-se como importante passo na desconstituição do mito "da última palavra".

\subsection{Da falta de contatos com os demais juízes e tribunais}

Essa dificuldade é constatada principalmente pela dificuldade de vinculação aos precedentes (verticais ou horizontais). Objetivando-se minimizar esse cenário, o Art. 24 estabelece a obrigação aos Tribunais de promoverem encontros periódicos (que podem ocorrer de forma presencial ou por videoconferência) com juízes envolvidos no controle jurisdicional de políticas públicas, a fim de proporcionar "[...] o conhecimento e possível harmonização de entendimentos sobre a matéria."

\subsection{Das dificuldades de ordem orçamentária}

Como apontado no decorrer do artigo, não há como desconsiderar que os direitos possuem seu custo e o Judiciário não pode desconhecê-lo. Por outro lado, não pode, como aponta o CNJ, ser refém do argumento econômico, mesmo que se reconheça um "[...] contexto de contingência dos programas e da necessidade de estabelecer prioridades de ação no âmbito do governo, é comum que o Estado condicione sua efetivação aos limites financeiros fáticos e à escassez de recursos." (ASENSI; PINHEIRO, 2015, p. 132).

Appio (2006, p. 72-73), de forma incisiva, pontua que "[...] não se pode afirmar que os juízes governam ou que tenham uma responsabilidade solidária junto com o Poder Executivo no 
equilíbrio do orçamento público." O autor prossegue e chama de "verdadeira negação de justiça" as decisões fundamentadas exclusivamente em razões de ordem econômica e no equilíbrio fiscal.

Observa-se, então, que, na fase preliminar, como elemento de informação, todos os requisitos que a autoridade pública deverá, por força do Art. 6º obrigatoriamente, informar ao juiz, contemplam cunho econômico. ${ }^{14}$ Nesse cerne, o questionamento permanece: até que ponto essas informações (munidas de comprovação inconteste) influenciarão na decisão judicial?

O Art. 18 apresenta dois exemplos de interferência direta no orçamento público. $\bigcirc$ primeiro tem-se como um acréscimo positivo do projeto, que é a possibilidade de determinação de apresentação do planejamento necessário à implementação ou correção da política pública objeto da demanda, instruído com o respectivo cronograma, sendo este debatido pelos atores envolvidos (juiz, Ente Público, parte e MP). Esse instrumento já é utilizado pelo Judiciário atualmente, porém, de forma tímida.

O segundo elemento, de constitucionalidade duvidosa, ${ }^{15}$ é a possibilidade de o juiz determinar ao Poder Público que inclua créditos adicionais especiais no orçamento do ano em curso ${ }^{16}$ ou, ainda, determinada verba no orçamento futuro. Assim, conjectura-se que a decisão judicial interferindo no orçamento do ano em curso encontre óbice na necessidade de autorização legislativa prevista no inciso V, do Art. 167 da Constituição Federal. ${ }^{17}$ Por outro lado, a possibilidade de determinação de inclusão no orçamento futuro (que já ocorre esporadicamente) configura-se como ponto positivo do projeto.

Enfim, reconhece-se que a questão orçamentária (e a questão da escassez de recursos) se aloca sempre entre os argumentos do Estado (e não poderia ser diferente). O CNJ, ao criticar o argumento econômico, expõe que "[...] o direito, portanto, passa não mais a ser visto de forma absoluta, podendo ser relativizado sob o argumento da insuficiência de recursos" (ASENSI; PINHEIRO, 2015) e que "[...] diversos profissionais do direito, estudantes, professores e doutrinadores tendem a 'se apaixonar' por este argumento e o reproduzirem de maneira ingênua e superficial." (ASENSI; PINHEIRO, 2015).

A última afirmação do Conselho Nacional de Justiça demanda visualização com ressalvas. No intuito de exemplificar o caso do direito à saúde, Aaron e Schwartz (1984, p. 81) afirmam que "[...] a questão da escassez se põe de maneira especial no acesso à saúde. Algumas pessoas podem

\footnotetext{
${ }_{14}$ Art. $6^{\circ}$ ": I - o planejamento e a execução existentes; II - os recursos financeiros previstos no orçamento para sua implementação; III - a previsão de recursos necessários a sua implementação ou correção; IV- em caso de insuficiência de recursos, a possibilidade de transposição de verbas; $\mathrm{V}$ - o cronograma necessário ao eventual atendimento do pedido." (CÂMARA DOS DEPUTADOS, 2014).

15 A respeito, ver o debate travado por Streck e Lima (2015), no artigo Lei das Políticas Públicas é "Estado Social a golpe de caneta?" e a réplica de Grinover, Lucon e Watanabe (2015) no artigo PL sobre controle jurisdicional de políticas públicas é constitucional. ${ }_{16}$ A Lei Orçamentária Anual (LOA) é um instrumento dinâmico e maleável, justamente para que se possa corrigir erros de planejamento e adequar as ações conforme a execução da política pública. Com isso, inevitavelmente, ocorrerá a necessidade de novas despesas e, consequentemente, de mais créditos orçamentários, os quais são denominados créditos adicionais. Os créditos adicionais se subdividem em créditos adicionais suplementares, créditos adicionais especiais e créditos adicionais extraordinários. Os créditos adicionais especiais se destinam a sanar um erro de planejamento (justamente a intenção do projeto - que é reparar um erro no planejamento orçamentário da política pública), quando não haja dotação orçamentária específica. Nesse caso, como se trata de despesa anteriormente não prevista, deverá passar pelo crivo do Poder Legislativo, sendo incluída na LOA como crédito especial, após nova aprovação por esse Poder em lei específica. Observa-se que o Poder Executivo fica adstrito ao crivo do Poder Legislativo (ALBUOUERQUE; MEDEIROS; SILVA, 2008, p. 207-208).

17 Art. 167. São vedados: [...] V - a abertura de crédito suplementar ou especial sem prévia autorização legislativa e sem indicação dos recursos correspondentes.
} 
pensar que, quando a saúde e a vida estão em jogo, qualquer referência a custo é repugnante, ou até imoral." Isso também é apontado por Holmes e Sunstein (2012, p. 43), quando estabelecem que "deveria ser evidente que os direitos têm um custo, mas, pelo contrário, a ideia soa como paradoxal, como falta de educação, quiçá como ameaça à preservação dos direitos."

A problemática relação entre direitos e orçamento fica mais acirrada no que se convencionou chamar de "tempos de crise". Pisarello (2009, p. 13), ao analisar os direitos sociais no contexto da crise financeira e econômica espanhola no mesmo ano, destaca as visíveis contradições mais agudas no discurso envolvendo os DESCs.

De um lado, esses direitos apresentam-se como instrumentos voltados à satisfação de necessidades básicas de pessoas e grupos, em especial daqueles em situação de maior vulnerabilidade "em tempos de crise". De outro, a concepção de que esses direitos são proclamados e incluídos nos textos jurídicos de maneira generosa, mas, na prática, pouco efetivados, principalmente sob o argumento da "escassez" (PISARELLO, 2009, p. 13).

Positivamente, o projeto reconhece, na esteira do já apontado por Amaral (2001, p. 147), que "[...] há menos recursos do que o necessário para o atendimento das demandas e que a escassez não é acidental." Com isso, "toma vulto a alocação de recursos", mesmo que as decisões alocativas se tornem "escolhas trágicas". Assim, a inteligência contida no Art. 18, de determinação de reserva no orçamento futuro, mostra-se como ponto de extrema importância na racionalização dos recursos e muito contribui à atuação judicial responsável.

\subsection{Das dificuldades oriundas da multiplicidade de ações individuais que vão inevitavelmente incidirão sobre as políticas públicas}

Talvez o maior desafio à concretização dos DESCs por intermédio de políticas públicas seja justamente a busca judicial individual pelo direito social. Por conseguinte, não há meio de desconsiderar o questionamento: como pode o juiz decidir se o caso A (judicializado) é mais importante que os casos B ou C (não judicializados), os quais estão em mesmas condições, no aguardo da concretização de seu direito? Indo além, como pode o juiz mensurar se, ao destinar o recurso para A, haverá recursos suficientes para a concretização do direito de B ou C ${ }^{18}$

Uma das críticas construídas em seção anterior justamente se direciona nessa vertente, da necessidade de modernização processual nos casos que envolvem os DESCs, eis que, regra geral, os instru-

\footnotetext{
18 Nesse sentido, é a observação de Ávila e Wierzchowski (2013, p. 196), as quais apontam que: "Cada vez que o Poder Judiciário a precia demandas individuais e emite decisão judicial no sentido de condenar o Estado ao pagamento de medicamentos indispensáveis à manutenção da saúde de determinado indivíduo, é certo que, para aquele demandante, o juiz está dotando da máxima eficácia algumas normas constitucionais que têm o sentido abstrato e apriorístico incerto. É o caso da norma que prevê que a dignidade da pessoa é fundamento da República (art. $1^{\circ}$, inc. III), assim como daquelas que preveem que a saúde é um direito fundamental social (arts. $6^{\circ}$ e 196, caput). Igualmente, está satisfazendo a norma contida no art. 5ª inc. XXXV, que determina que a função essencial do Poder Judiciário é apreciar a lesão ou ameaça de lesão a direito que lhe seja submetida pelo titular. Sendo assim, no intuito de preservar a dignidade e a saúde, e de se desincumbir de sua missão constitucional, os juízes condenam o Estado ao pagamento de prestações a esses indivíduos. Tudo para satisfazer o caso que lhe é individualmente apresentado."
} 
mentos disponíveis voltam-se à individualidade. Pois bem, o projeto de lei, objetivando reduzir o número de ações individuais, apresenta a inovação da "ação coletiva", cuja decisão terá efeito erga omnes.

Essa previsão está contida no Art. 30 e estabelece que, em razão da relevância social, após ouvido o Ministério Público, a ação individual poderá ser convertida em coletiva, desde que: esta tenha efeitos coletivos, ou seja, quando se trate de bem jurídico coletivo e indivisível e a ofensa afete além do indivíduo a coletividade; e objetive a solução de conflitos que abranjam uma relação jurídica plurilateral, que necessite de solução uniforme (por natureza ou força de lei), com tratamento isonômico a todos os membros dessa coletividade, impondo-se uma conduta consistente e unitária à parte demandada.

Esse acréscimo compreende significância, podendo contribuir consideravelmente à efetivação "coletiva" dos DESCs, sem descaracterizar sua dimensão subjetiva. Coaduna-se mais ainda ao status de direito público subjetivo reconhecido pelo STF, como no caso da judicialização da saúde.

Outro ponto trazido pelo projeto, que obriga a uma reflexão cautelosa, está contido na possibilidade de reunião de processos (em $1^{\circ}$ grau, prevista no Art. 23, e, em grau de recurso, prevista no Art. 25). Em ambos os casos, existe a possibilidade de, independente de conexão, haver julgamento conjunto (em $1^{\circ}$ grau ou no Tribunal), quando se tratar de pedido de implementação ou correção de políticas públicas arroláveis ao mesmo ente, em processos que tramitem em diferentes juízos (ou órgãos especiais dos Tribunais), a fim de que seja proferida uma decisão equitativa e exequível (CÂMARA DOS DEPUTADOS, 2014).

O temor é que, embora se trate de controle de políticas públicas, ao fim, o que está em jogo é a concretização de um direito fundamental, e este deve ser analisado caso a caso. A exemplo do direito à saúde, nem todo o paciente que se encontre necessitado de determinado procedimento está em idêntica situação. Não se quer dizer que o direito à saúde de A é mais importante que o direito à saúde de $\mathrm{B}$.

Em outras palavras, expressa que, por exemplo, um simples pedido judicial de AAS infantil, em ações individuais, propostas pelos cidadãos A e B, em que seja demandado o Estado do Rio Grande do Sul, poderá representar fins absolutamente diferentes, pois ao cidadão A pode ter sido prescrito para a melhora de um quadro de resfriado, enquanto ao cidadão B objetiva ao tratamento de um sério problema cardiovascular. Então, estar-se-ia proferindo uma decisão equitativa, deferindo-se conjuntamente ambos os pedidos?

O receio apresentado segue na esteira de uma das conclusões do Conselho Nacional de Justiça, no que se refere ao direito à saúde, de que o cidadão não pode ser tratado como um número. O desafio a essa mudança de concepção está na superação da "[...] tradição intervencionista das políticas de saúde no Brasil" (ASENSI; PINHEIRO, 2015, p. 136). Nesse sentido, afirma-se: o desafio justamente não é saber se o direito poderá ser concretizado pelo Poder Judiciário (isso já foi superado), mas como efetivá-lo em cada caso específico.

Por fim, há de se dizer que o projeto que objetiva a criação de um processo especial para o controle jurisdicional de políticas públicas apresenta um avanço considerável no sentido de instrumentalizar o que, na prática, em parte, já ocorre. Como visto, essa é uma necessidade apontada pela 
doutrina, que critica um relativo atraso nos meios processuais voltados à concretização dos Direitos Econômicos, Sociais e Culturais.

O projeto, embora demande aprimoramentos, como os já pontuados, compreende virtudes com significativa importância, entre elas a possibilidade da ação coletiva. De resto, instrumentaliza práticas que já ocorrem (ou deveriam ocorrer) no âmbito do Poder Judiciário, a exemplo dos princípios positivados no Art. $2^{\circ}$. Assim, questiona-se: afinal, algum destes, atualmente, deve ser desconsiderado ou é desconhecido pelo juiz?

Ademais, surgirão questionamentos, principalmente quanto à relevância e à quantificação das informações e comprovações apresentadas pelo Poder Público na servência da construção da decisão que controlará uma política pública. Com isso, mudará o cenário atual? $\bigcirc$ aspecto econômico-financeiro será considerado?

São questionamentos que serão respondidos com o aprimoramento das práticas estabelecidas no projeto, entre elas o diálogo interinstitucional, que deverá ocorrer mais intensamente como forma de relação horizontal e não como mero exercício do direito ao contraditório e à ampla defesa (ponto que demanda atenção especial no aprimoramento do projeto).

\section{Conclusão}

Diante de todo o exposto, conclui-se que os direitos fundamentais possuem identidade única, contemplando tanto uma dimensão objetiva quanto uma subjetiva, bem como uma dimensão negativa ao passo que positiva, de forma a não estabelecer uma dicotomia entre os direitos civis e políticos e os direitos econômicos, sociais e culturais.

Os DESCs constituem-se direitos que possuem custos e isso não pode ser desconsiderado, na mesma proporção que os direitos civis e políticos também os possuem, incidindo, assim, diretamente no orçamento público e acarretando necessidade de planejamento responsável e com a correspondente alocação dos recursos.

A doutrina pesquisada e o Supremo Tribunal Federal reconhecem que se tratam de direitos subjetivos, ou seja, efetivados individualmente, mesmo que dentro de uma coletividade, o que possibilita a busca individual em face ao Poder Judiciário.

Assim, ao efetivá-los, o Judiciário acaba por interferir nas políticas públicas (que constituem forma natural de realização), principalmente com o número de ações individuais levadas à apreciação, como apontado no relatório de pesquisa realizado pelo Conselho Nacional de Justiça publicado em 2015.

A problemática da efetivação dos DESCs pela jurisdição reside, muitas vezes, como constatado no decorrer do presente artigo, na necessidade de aprimoramento dos meios processuais empregados na tutela desses direitos, os quais, tradicionalmente, foram pensados pelo viés dos direitos civis e políticos (individuais).

Com efeito, a propositura de um projeto de lei objetivando estabelecer um processo especial para o controle jurisdicional de políticas públicas demonstra importante avanço nesse caminho, 
principalmente com a possibilidade de conversão da ação individual em coletiva. Por certo que o projeto necessita de aprimoramentos, principalmente em relação à horizontalidade do diálogo interinstitucional e ao controle judicial do orçamento público (em especial do ano em curso, já em fase de execução).

Ademais, o projeto contempla práticas que, embora já estejam em utilização em maior ou menor escala, passarão a ser procedimentalizadas e pautarão a atuação judicial, no intuito de superar dificuldades atuais, muitas destas apontadas pelo próprio CNJ. Resta saber se, na prática, serão realizáveis e confiáveis, como o estabelecimento do Cadastro Nacional de Processos sobre Políticas Públicas.

Por último, necessário se faz afirmar que, se é verdade que a implantação e a implementação das políticas públicas cabem aos Poderes políticos, não menos verdadeira é a afirmação de que o Judiciário não pode se abster de efetivar o direito fundamental. Assim, um processo judicial que considere a lógica orçamentária, com a responsável alocação de recursos e sua efetiva comprovação, com a possibilidade de tutela coletiva do DESC, tem muito a contribuir não apenas para a concretização dos direitos fundamentais, mas também para o próprio fortalecimento do Estado Democrático de Direito.

\section{Referências}

AARON, Henry J.; SCHWARTZ, William B. The Painful Prescription: rationing hospital care. Washington: The Brookings Institution, 1984.

ABRAMOVICH, Víctor; COURTIS, Christian. Apuntes sobre la exigibilidad judicial de los derechos sociales. In: ABRAMOVICH, Víctor; AÑÓN, María José; COURTIS, Christian (Comp.). Derechos Sociales: instrucciones de uso. Ciudad de México, Fontamara, 2003.

ABRAMOVICH, Víctor; COURTIS, Christian. Los derechos sociales como derechos exigibles. Madrid: Editorial Trota, 2002.

AlbuQUerQue, Claudiano Manoel de; MEDEIROS, Márcio Bastos; SILVA, Paulo Henrique Feijó da. Gestão de Finanças Públicas: fundamentos e práticas de planejamento, orçamento e administração financeira com responsabilidade fiscal. 2. ed. Brasília, DF: Finanças Públicas, 2008.

AMARAL, Gustavo. Direito, Escassez \& Escolha: em busca de critérios jurídicos para lidar com a escassez de recursos e as decisões trágicas. Rio de Janeiro: Renovar, 2001.

APPIO, Eduardo. Controle Judicial de Políticas Públicas no Brasil. 2. reimp. Curitiba: Juruá, 2006.

ARANGO, Rodolfo. El concepto de Derechos Sociales Fundamentales. Bogotá: Legis, 2005.

ASENSI, Felipe Dutra; PINHEIRO, Roseni (Coord.). Judicialização da saúde no Brasil: dados e experiência. Brasília, DF: CNJ, 2015. 
ÁVILA, Ana Paula Oliveira; WIERZCHOWSKI, Mariana Ruschel. "Fair play" judicial na efetivação dos direitos sociais: da crítica ao ativismo judicial concretista à defesa do controle material das leis orçamentárias pelo Poder Judiciário. Revista Direitos Fundamentais \& Justiça, Porto Alegre: HS, v. 7 , n. 23, 2013.

BARRETTO, Vicente de Paulo. Reflexões sobre os direitos sociais. Revista Quaestio Iuris, Rio de Janeiro: UERJ, v. 1, n. 6-9, 2012.

BÖCKENFÖRDE, Ernest Wolfgang. Escritos sobre Derechos Fundamentales. Tradução Juan Luis Requejo Pagés e Ignacio Vllaverde Menéndez. Aufi-Baden-Baden: Nomos Verlagsgesellschaft, 1993.

BRASIL. Constituição Politica do Imperio do Brazil (de 25 de março de 1824). Manda observar a Constituição Politica do Imperio, offerecida e jurada por Sua Magestade o Imperador. Rio de Janeiro, 22 abr. 1824. Disponível em: <https://www.planalto.gov.br/ccivil_03/constituicao/constituicao24. htm >. Acesso em: 25 jul. 2015.

BUCCI, Maria Paula Dallari. Fundamentos para uma teoria jurídica das políticas públicas. São Paulo: Saraiva, 2013.

BUCCI, Maria Paula Dallari. O conceito de política pública em direito. In: BUCCI, Maria Paula Dallari (Org.). Políticas públicas - reflexões sobre o conceito jurídico. São Paulo: Saraiva, 2006.

CÂMARA DOS DEPUTADOS. Projeto de Lei n. 8.058, de 2014. Institui processo especial para o controle e intervenção em políticas públicas pelo Poder Judiciário e dá outras providências. Brasília, DF: Câmara dos Deputados, 2014. Disponível em: <http://www.camara.gov.br/proposicoesWeb/ prop_mostrarintegra;jsessionid=C22A085420C09554A1375205719BD24A.proposicoesWeb1?codteor $=1284947 \&$ filename $=$ Avulso $+-P L+8058 / 2014>$. Acesso em: 25 jul. 2015.

CANOTILHO, Joaquim José Gomes. Metodologia 'fuzzy' e camaleões normativos. In: CANOTILHO, Joaquim José Gomes (Org.). Estudos sobre Direitos Fundamentais. Coimbra: Ed. Coimbra, 2004.

GARGARELLA, Roberto. El nuevo constitucionalismo dialógico frente al sistema de los frenos y contrapesos. In: GARGARELLA, Roberto (Comp.). Por una justicia dialógica: El Poder Judicial como promotor de la deliberación democrática. Buenos Aires: Siglo Veintiuno, 2014.

GAVARA DE CARA, Juan Carlos. La dimensión objetiva de los derechos sociales. Barcelona: Bosch Editor, 2010.

GRINOVER, Ada Pellegrini; LUCON, Paulo Henrique dos Santos; WATANABE, Kazuo. PL sobre controle jurisdicional de políticas públicas é constitucional. Revista Consultor Jurídico, 23 fev. 2015. Disponível em: <http://www.conjur.com.br/2015-fev-23/pl-controle-jurisdicional-politica-publica-constitucional>. Acesso em: 26 jul. 2015.

HOLMES, Stephen; SUNSTEIN, Cass R. El costo de los derechos: po qué la liberdad depende de los impuestos. Tradução Stella Mastrangelo. Buenos Aires: Siglo Veintiuno, 2012.

LANGFORD, Malcolm. Judicialização dos Direitos Econômicos, Sociais e Culturais no Âmbito Nacional: Uma Análise Socio-Jurídica. Tradução Thiago Amparo. SUR - Revista Internacional de direitos Humanos, v. 6, n. 11, 2009.

OLIVEIRA, Régis Fernandes de. Curso de Direito Financeiro. São Paulo: Revista dos Tribunais, 2006. 
PISARELLO, Gerardo. Los derechos sociales y sus garantías: elementos para una reconstrucción. Madrid: Editorial Trotta, 2007.

PISARELLO, Gerardo. Los derechos sociales y sus "enemigos": elementos para una reconstrucción garantista. In: VALIÑO, Vanessa (Coord.). Defender y repensar los derechos sociales en tiempo de crisis. Barcelona: Observatori DESC, 2009.

SARLET, Ingo Wolfgang. A titularidade simultaneamente individual e transindividual dos direitos sociais analisada à luz do exemplo do direito à proteção e promoção da saúde. Revista Direitos Fundamentais \& Justiça, Porto Alegre: PUCRS, n. 10, 2010.

SARLET, Ingo Wolfgang. Os direitos sociais como direitos fundamentais: contributo para um balanço aos vinte anos da Constituição Federal de 1988. In: SOUZA NETO, Cláudio Pereira de, SARMENTO, Daniel, BINENBOJM, Gustavo (Coord.). Vinte Anos da Constituição Federal de 1988. Rio de Janeiro: Lumen Juris, 2009.

SCHMIDT, João Pedro. Para entender as políticas públicas: aspectos conceituais e metodológicos. In: REIS, Jorge Renato dos; LEAL, Rogério Gesta (Org.). Direitos sociais e políticas públicas: desafios contemporâneos. Santa Cruz do Sul: Ed. Unisc, 2008.

STRECK, Lenio Luiz; LIMA, Martonio Mont'Alverne Barreto. Lei das Políticas Públicas é "Estado Social a golpe de caneta?" Revista Consultor Jurídico, 10 fev. 2015. Disponível em: <http://www. conjur.com.br/2015-fev-10/lei-politicas-publicas-estado-social-golpe-caneta >. Acesso em: 26 jul. 2015 .

Data da submissão: 31 de janeiro de 2016 Avaliado em: 3 de setembro de 2016 (AVALIADOR A) Avaliado em: 6 de dezembro de 2016 (AVALIADOR B) Aceito em: 6 de dezembro de 2016 